\title{
Experiências de Tecnologia Social na modalidade reciclagem no Brasil e na Colômbia: como as redes afetam sua reaplicabilidade.
}

\author{
Thayla B. de Souza, Paulo V. Noije.
}

\section{Resumo}

Em um contexto de altas taxas de desemprego, a reciclagem é uma das soluções para esse problema, pois gera renda à população mais carente. Na Colômbia e no Brasil, há experiências de Tecnologia Social (TS), que na modalidade de reciclagem geraram renda. No entanto, pouco se sabe sobre quais organizações são responsáveis pela sua realização, e menos ainda se conhece quais redes foram originadas a partir delas e se essas redes afetam a reaplicabilidade das experiências. Com isso, foi realizado uma ampla pesquisa, sendo encontradas 121 experiências de Tecnologia Social que geraram renda, sendo selecionadas para estudo 2 delas, sendo uma de cada pais. O objetivo foi compreender como as redes afetam a reaplicabilidade das experiências de TS na modalidade reciclagem, por meio de um questionário online aplicado aos atores responsáveis pelas tecnologias escolhidas. Além disso, o presente estudo foi realizado no âmbito do Laboratório de Estudos do Setor Público (LESP), fazendo parte de uma pesquisa maior em que se objetivou realizar um estudo comparativo entre experiências de TS nas modalidades: alimentação, geração de renda, habitação e meio ambiente, recursos hídricos e energia, nos países: México, Argentina, Brasil e Colômbia.

Palavras-chave: Tecnologia Social, reaplicabilidade, redes.

\section{Introdução}

Sabe-se que o desemprego, de diferentes maneiras, atinge a totalidade dos trabalhadores, sejam homens ou mulheres, nativos ou imigrantes (ANTUNES, 2010), sendo assim um dos principais problemas econômicos. Dentro desse contexto, a Tecnologia Social (TS) é vista como uma solução, pois "se apresentam como alternativas modernas, simples e de baixo custo para a solução de problemas estruturais das camadas mais excluídas da sociedade" (COSTA, 2013, p.6).

A TS é definida pela Fundação Banco do Brasil (2018, p.1) como aquela que “... compreende produtos, técnicas reaplicáveis, desenvolvidas na interação com a comunidade e que representem efetivas soluções de transformação social". Sendo a reaplicação, a aplicação da TS em diferentes lugares considerando que em cada contexto o uso da tecnologia será adaptado (COSTA, 2013).

Levando em consideração que as redes funcionam também como meio de compartilhamento de informação e conhecimento (TOMAÉL; ALCARÁ \& DI CHIARA, 2005), e que a partir de sua estrutura é possível racionalizar recursos, aumentar o valor dos recursos existentes e reduzir custos (LOPES \& BALDI, 2009), é de suma importância compreender como as redes afetam a reaplicabilidade. Sendo este o objetivo desta pesquisa.

\section{Resultados e Discussão}

Com o questionário online, se obteve 2 respostas, sendo uma de uma experiência do Brasil e outra da Colômbia. A partir delas foi possível identificar algumas semelhanças entre as experiências, que podem ser entendidas como pré-requisitos para a reaplicação. Sendo elas: A presença de voluntários na construção e na manutenção da TS; Financiamento próprio; Apoio de universidades; Uso de e-mail e telefone para comunicação; Apoio do governo e presença de recursos financeiros.

\section{Conclusões}

A partir da analise das redes de cada experiência, podese dizer que cada uma delas possui um hiperconector, sendo ela uma conexão na rede que serve de atalho para os demais pontos (MARTINHO, 2003). Sendo a da experiência "Veículo de tração mista" a Universidade, como ilustra a figura 1 e da experiência "Terrarum ecológico" a empresa Terrarum, como ilustra a figura 2, pois foram esses elementos da rede que facilitaram as conexões, possibilitando o desenvolvimento da TS. Com isso, vislumbra-se que o desenvolvimento e a reaplicação da TS são mais propícios quando existe um hiperconector.

Figura 1. Rede da experiência: Veículo de tração mista.

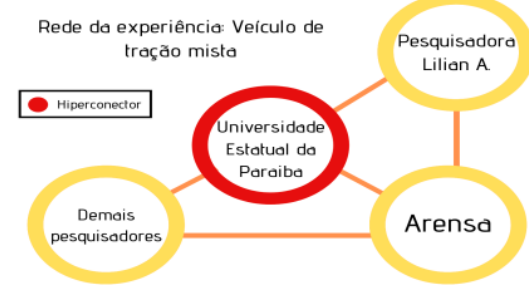

Fonte: elaboração própria.

Figura 2. Rede da experiência: Terrarum ecológico.

Rede da experiência: Terrarum ecológico

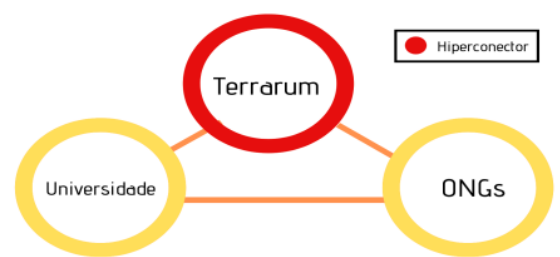

Fonte: elaboração própria.

\section{Agradecimentos}

Ao CNPq/Capes pelo apoio financeiro a este trabalho.

ANTUNES, R. (2010). A crise, o desemprego e alguns desafios atuais. Serviço Social \& Sociedade. São Paulo.

COSTA, A. B. et al. Tecnologia Social e Políticas Públicas. São Paulo: Instituto Pólis Brasília: Fundação Banco do Brasil, 2013.

Fundação Banco do Brasil (2018). Disponível em: tecnologiasocial.fbb.org.br. Acessado em: abril de 2018 .

LOPES, F. DIAS; BALDI, M. Redes como perspectiva de análise e como estrutura de governança: uma análise das diferentes contribuições. Revista de Administração Pública, v. 43 , n. 5, p. 1007-1035, out. 2009.

Martinho, Cássio. Redes: uma introdução às dinâmicas da conectividade e da autoorganização. Rebeca Kritsch (WWF-Brasil). 2003.

TOMAÉL, M. I.; ALCARÁ, A. R.; DI CHIARA, I. G. Das redes sociais à inovação. Ciência da Informação, v. 34, n. 2, p. 93-104, ago. 2005. 